\title{
Comparison of 1-D and 2-D Tests in Geotextile Dewatering Applications
}

\author{
J. Driscoll ${ }^{1}$ P. Rupakheti ${ }^{2} \cdot$ S. K. Bhatia ${ }^{2} \cdot$ M. M. Khachan ${ }^{2}$
}

Received: 2 July 2016/ Accepted: 16 August 2016/Published online: 1 September 2016

(C) Springer International Publishing Switzerland 2016

\begin{abstract}
In this study, two different one-dimensional tests (only vertical flow) (pressure filtration test and suction filtration test) were compared to determine variability in the results due to different forms of pressure application. In addition, an innovative two-dimensional filtration apparatus (with both vertical and radial flow) was developed in order to determine the effect of radial flow on the results. This apparatus will more accurately imitate the real-life dewatering application of geotextile tubes. Unlike on-site "hanging bag" and "pressurized geotextile dewatering" tests, this laboratory apparatus was designed in a form that will facilitate the studying of dewatering rate vertically and radially separately. It will also be used by mathematicians, as its geometric form will be more conducive to the analysis of dewatering. This will aid in the creation of a simple and fast mathematical model to determine geotextile dewatering rate, which will reduce the need and cost of experimental testing during prior to actual dewatering in the site.
\end{abstract}

\section{P. Rupakheti \\ prupakhe@syr.edu \\ J. Driscoll \\ jdrisc01@syr.edu \\ S. K. Bhatia \\ skbhatia@syr.edu \\ M. M. Khachan \\ mmkhacha@syr.edu}

1 Environmental Resources Engineering, SUNY College of Environmental Science and Forestry, Syracuse, NY 13244, USA

2 Department of Civil and Environmental Engineering, Syracuse University, 151 Link Hall, Syracuse, NY 13244, USA
Keywords Geotextile $\cdot$ Geotextile tube $\cdot$ Dewatering rate One-dimensional $\cdot$ Two-dimensional $\cdot$ Dredging $\cdot$ Filter cake

\section{Introduction}

Geotextile tubes have been widely used around the world to contain and dewater high water content contaminated slurries and industrial and municipal sludge [1], mine tailings, fly ash [2]. Dredged sediment from water bodies is pumped into geotextile tubes where the water freely drains while sediment are retained. After multiple fillings and subsequent dewatering, the filter cake formed from the retained sediments is allowed to consolidate. Following the consolidation, the geotextile tubes are left in place and capped, or hauled to the landfill facility for disposal.

Various type of performance tests have been conducted to understand the dewatering performance of the slurry at full scale. The performance tests are small-scale laboratory tests performed on small representative sample of the slurry, or medium scale that may be performed in the lab or field [3]. These tests not only help to characterize the sample and provide information about dewatering efficiency, but also aids in finding the optimum dose of chemical conditioner keeping in mind the project guidelines and specifications. The small scale tests that have been widely used are pressure filtration test (PFT), suction or vacuum filtration test, and the falling head test (FHT). PFT have been used by many researchers to assess the dewatering performance [2, 4-10]. Some study using vacuum filtration test has also been performed [11]. Others have used FHT to simulate dewatering through the geotextile [12]. The PFT setup consists of a cylindrical acrylic reservoir and threaded base plate that holds the geotextile 
and directs the filtrate flow. Air is applied to the reservoir using compressed air in the laboratory. The effluent is measured using a digital scale, and following dewatering, the filter cake properties such as solids content, height are measured. Typical vacuum filtration setup is composed of a plastic permeameter that holds the geotextile in place, and a vacuum pump that supplied the required vacuum pressure below the geotextile-slurry interface. In both PFT and vacuum filtration tests, the flow through the geotextile is only vertical. As a result, these tests help to predict only the vertical dewatering rate. However, in real dewatering application the flow takes place both vertically and radially. Hence, a test setup that can incorporate vertical and radial flow can help to better understand the dewatering rate as well as filter cake properties.

Some of the commonly used medium-scale tests are hanging bag test (HBT) and geotextile tube dewatering test (GDT). HBTs and pilot tube tests have been used in situ to determine the filtration rate, soil loss, and filter cake properties of the site-specific sediment [3]. Hanging bag tests are commonly used in the field to predict dewatering performance $[2,5,13]$. Hanging bag tests are open to the air at the top, where the slurry is added and dewaters radially and vertically by gravity while filtration rate is recorded. To simulate real dewatering applications, a second filling is added at the same volume and concentration after the first filling ends. After the two fillings, filter cake properties including solids content, soil loss, and turbidity are recorded. In HBT, the dewatering rate cannot be separated in vertical and radial directions.

More recently, GDT has been more commonly used to assess the dewatering performance as it visualizes the dewatering process, and simulates the transport of flocculated sediment through pipeline elbows and valves. In addition to creating representative samples of filter cake and the filtrate, this tests confirms the chemical conditioning dose of full scale application. Grzelak et al. [3] compared the lab scale tests (FHT and PFT) with medium scale tests (HBT and GDT) using a woven geotextile and silt slurry at $33 \%$ solids concentration. It was found out that the dewatering efficiency was similar for the PFT, HBT, and GDT, while filtration efficiency was similar for the HBT and GDT. However, FHT was determined to be a poor indicator to assess the dewatering performance compared to other test methods studied. The dewatering efficiency is defined by the following relation
Dewatering efficiency $=\frac{\left(\% \text { Solids }_{\text {final }}-\% \text { solids }_{\text {initial }}\right) \times 100 \%}{\% \text { Solids }_{\text {initial }}}$

However, the dewatering efficiency provides information about the final solid content of the filter cake as compared to the solid content of the slurry. Information about the dewatering rate (vertical or radial is not compared).

In order to understand the vertical as well as radial flow during dewatering, a new laboratory two dimensional filtration apparatus at Syracuse University was developed. The apparatus is geometrically designed to separate radial from vertical drainage areas in order to determine the ratio and rate of radial vs. vertical dewatering. These results from the test will be of great use in the laboratory, as it will provide for more accurate dewatering rate and filter cake property analysis. These results from the test will be of great use in the laboratory, as it will provide for more accurate dewatering rate and filter cake property analysis. This apparatus aims to address some of the limitations of the PFT and vacuum filtration tests used in the laboratory.

\section{Materials}

\section{Soils}

The soils used for this study were obtained from Clarks Aggregate Co., a local quarry located at Tully, NY. The coarse soil, identified as Tully sand, was prepared by removing fractions coarser than US sieve No. 4. The sediment contains $92 \%$ sand and silt, and about $8 \%$ clay particles. The sediment was found to be non-plastic and classified as SP-SM. The properties of soil are given in Table 1.

\section{Flocculant}

Zetag 8185 anionic polyacrylamide copolymer was found to be the optimum flocculant for Tully sand, at a dose of 200 ppm. A Phipps and Bird PB-700 Jartester with four large paddle mixers were used to mix the sediment, DI water, and polymer together. All tests were mixed with polymer to enhance flocculation.

Table 1 Tully sand properties

\begin{tabular}{llllllll}
\hline Property & $D_{10}(\mathrm{~mm})$ & $D_{30}(\mathrm{~mm})$ & $D_{60}(\mathrm{~mm})$ & $C_{u} *$ & $C_{c} *$ & $S_{o}^{*}\left(\mathrm{~m}^{2} / \mathrm{kg}\right)$ & USCS classification \\
\hline Tully sand & 0.007 & 0.077 & 0.13 & 18 & 6.51 & 438.12 & $S P-S M$ \\
\hline$* C_{u}$ coefficient of uniformity $=D_{60} / D_{10} ; * C_{c}$ coefficient of curvature $=\left(D_{30}\right)^{2} /\left(D_{10}\right)\left(D_{60}\right)$ \\
$* S_{o}$ is the specific surface area
\end{tabular}




\section{Geotextile}

A high strength polypropylene (PP) woven monofilament geotextile commonly used in dewatering was selected for this study and was provided by TenCate. This geotextile has an apparent opening size (AOS) and permittivity compatible with the Tully sand when flocculated. The physical and hydraulic geotextile properties are presented in Table 2.

\section{Test Methods}

\section{Pressure Filtration Test}

The PFT setup has been shown in Fig. 1. PFT consists of a cylindrical reservoir $(72 \mathrm{~mm}$ diameter, $170 \mathrm{~mm}$ height, and $600 \mathrm{~mL}$ volume capacity) and threaded container that secures the geotextile in place. A $547.17 \mathrm{~mL}$ slurry at $20 \%$

Table 2 Physical and hydraulic geotextile properties

\begin{tabular}{ll}
\hline Material & Polypropylene $(P P)$ \\
\hline Fabric structure & $W, M F$ \\
AOS $(\mathrm{mm})$ & 0.42 \\
Permittivity $\left(\mathrm{s}^{-1}\right)$ & 0.37 \\
Mass per unit area $\left(\mathrm{g} / \mathrm{m}^{2}\right)$ & 585 \\
Thickness $(\mathrm{mm})$ & 1.04 \\
Tensile strength $(\mathrm{kN} / \mathrm{m})$ & $96 \times 70$ \\
\hline
\end{tabular}

$W$ woven, $M F$ monofilament, $A O S$ apparent opening size solids concentration of Tully sand and optimum dose of zetag 8185 flocculants was mixed together in a Phipps and Bird Jartester at $220 \mathrm{rpm}$. After mixing, the slurry was quickly transferred into the cylindrical reservoir and the cap was screwed. The reservoir was placed into the holding apparatus and the pressure hose was connected using lab supplied compressed air at $5.51-6.89 \mathrm{kPa}$, and this pressure was held constant throughout the test. This pressure represents the internal pressure during dewatering of geotextile tubes. As in geotextile tubes, pressure naturally lessens on the system as water level decreases during dewatering. To begin, the dewatering valve was released to initial dewatering. After the first filling, the air pressure was reduced, the cap removed, and the second filling of the same concentration and volume was added; after which the system was returned to its dewatering state and filtration continues. Effluent volume was measured during both first and second fillings using a $500 \mathrm{~mL}$ graduated cylinder. At the end of the PFT, the filter cake was immediately taken from the reservoir and the filter cake height was measured. The samples were weighed then were oven dried for $24 \mathrm{~h}$ to measure its moisture content and percent solid of the filter cake.

\section{Suction Filtration Test}

The suction filtration test has been used in the lab to simulate dewatering of pulp using a nylon mesh filter [14] and has been shown in Fig. 2. Within the drainage basin there is a geotextile housing unit that holds a removable threaded metal plate. A large metal filter is below the geotextile to

Fig. 1 PFT test set up [15]

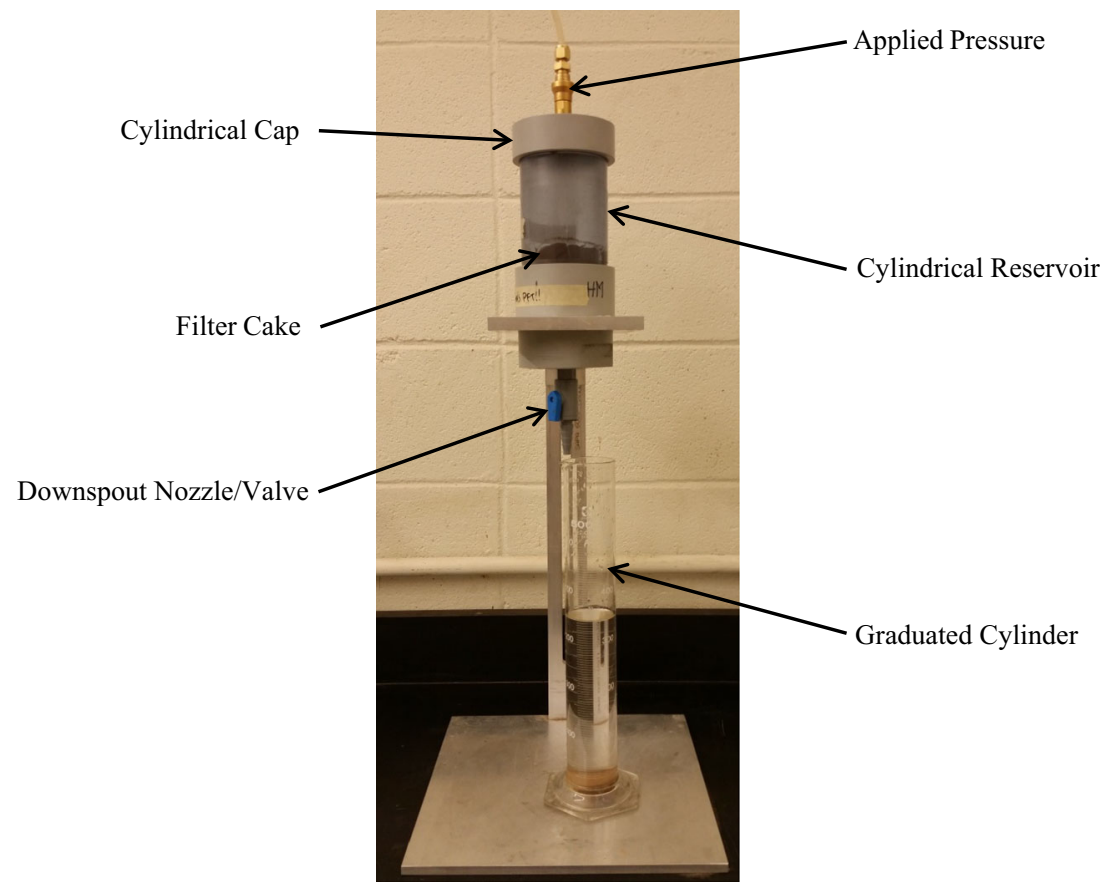


Fig. 2 Suction filtration test setup

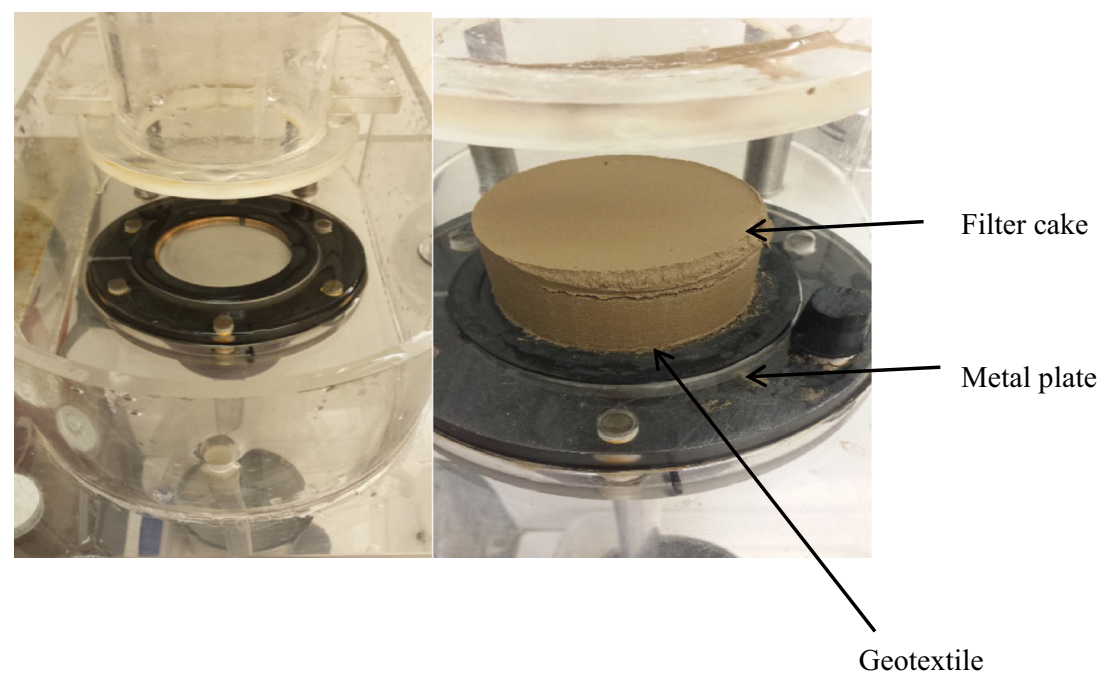

keep it steady, and then a metal topper is screwed down onto the geotextile in the plate to secure it in place. The cylindrical metal plate can then be added into the housing unit. The apparatus also consists of a voltage reader held at the top of the apparatus above the cylindrical reservoir to record voltage measurements as slurry level drops and that can be converted into height measurements after testing. A drainage basin is used to connect the cylindrical reservoir and funnel to fill the second reservoir and top off the geotextile housing unit with DI water before addition of the slurry. Slurry can be added directly into the cylindrical reservoir which has clamps to release and snap it down onto a rubber component on top of the geotextile housing unit to ensure a water tight apparatus. Data is recorded as the rubber stopper is removed to initiate dewatering.

A $1094.34 \mathrm{~mL}$ slurry at $20 \%$ solids concentration of Tully sand was mixed together in a Phipps and Bird Jartester at $220 \mathrm{rpm}$. The slurry was then added quickly into the apparatus and sits at the bottom of the first cylindrical reservoir. The rubber stopper at the bottom of the second reservoir was removed to initiate dewatering through suction. As water drains into the second reservoir, volume does not change, therefore suction pressure was constant. Effluent volume was measured continuously during the tests. Filter cake properties and quality of effluent were recorded at the end of the test.

Both the PFT and suction filtration test accomplish dewatering through application of a known pressure in vertical direction only. However, instead of air being supplied at the top of the apparatus as in the PFT, this method uses a suction pressure of $5.51 \mathrm{kPa}$ over the second reservoir to dewater the sediment. This is done by filling the second reservoir with de-aired water, creating a constant pressure head throughout the entire test. In this study the results will be compared.

\section{Two-Dimensional Filtration Test}

The Two- Dimensional Filtration device has been developed at Syracuse University to measure dewatering rate of the slurry in radial and vertical direction in a laboratory environment and is shown in Fig. 3. Radial results were those recorded from filtering through the sides of the geotextile, while the vertical results are those recorded through the bottom of the geotextile, as well as through the filter cake once it has formed. Unlike a HBT used in the field, this test allows the determination of radial and vertical dewatering rate as well as filter cake properties. The apparatus consists of a woven geotextile molded to form a radial cylinder of geotextile with a geotextile base. The geotextile cylinder is designed of a height of $60 \mathrm{~cm}$ to create a pressure of $5.51 \mathrm{kPa}$ only through the addition of slurry at the start of the test, which decreases as dewatering proceeds. The geotextile cylinder is $15 \mathrm{~cm}$ in diameter, housed $3 \mathrm{~cm}$ below the top of a drainage basin that is $30 \mathrm{~cm}$ in diameter. The drainage basin is raised above the ground on four legs. Two center drainage pipes collect vertical effluent that collects into a beaker, while four drainage pipes in the drainage basin collect radial effluent that collects into a large container on top of a balance to record measurements.

For each filling, two sets of $4956 \mathrm{~mL}$ slurry (a total of $9912 \mathrm{~mL}$ per filling, nine times more than used in PFT and Suction Filtration tests) at $20 \%$ solids concentration was mixed together in two separate containers, as this was more practical for such a large volume. For the first filling, the slurry was added to the apparatus in two stages in quick succession. After dewatering slows to almost zero, the second batch of the slurry was mixed and added. Measurements of the radial dewatering rate were taken continuously during the tests, while vertical dewatering rate 
Fig. $32-D$ test setup

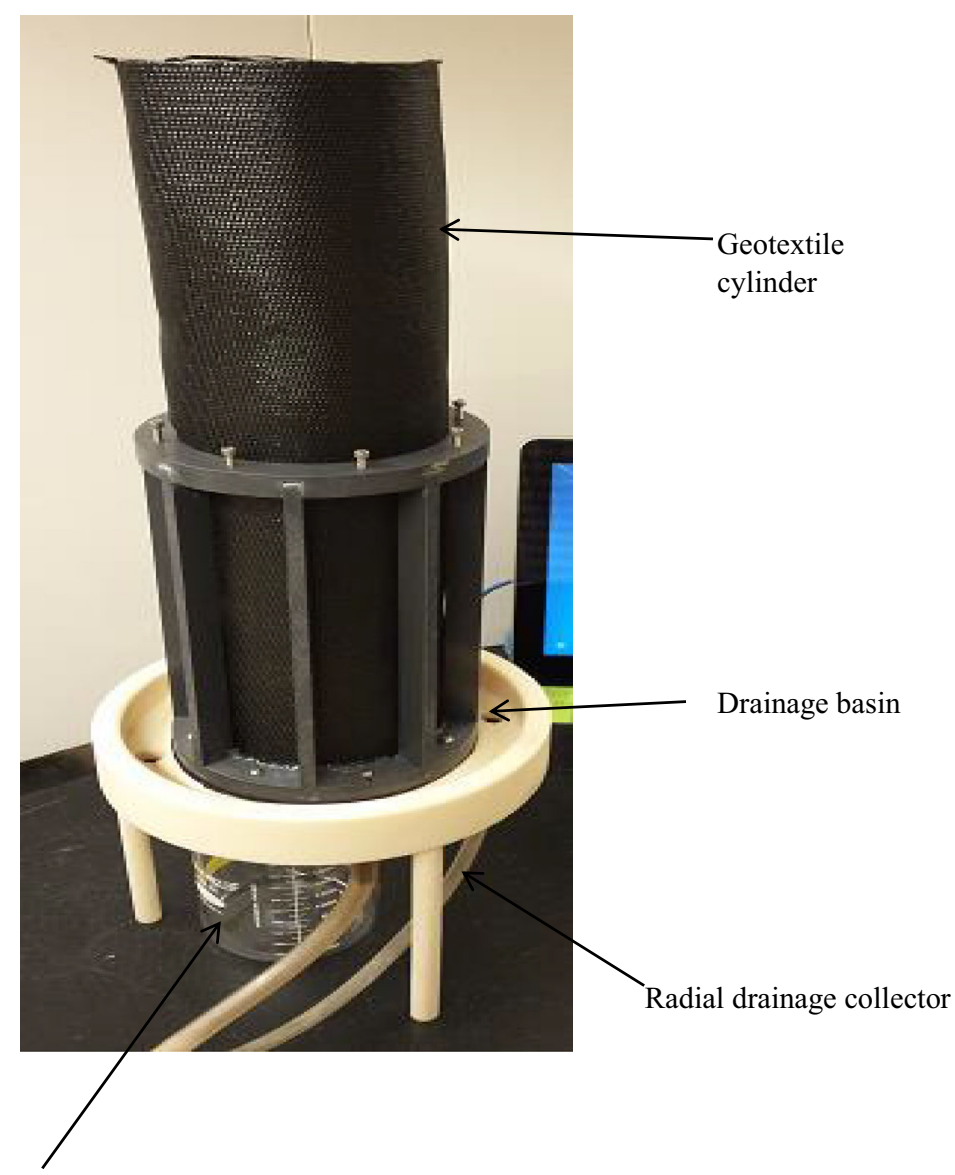

Vertical drainage collecting beaker

Table 3 Test volume comparison

\begin{tabular}{llll}
\hline & PFT $(\mathrm{mL})$ & $\begin{array}{l}\text { Suction filtration } \\
\text { test }(\mathrm{mL})\end{array}$ & $\begin{array}{l}\text { 2D Filtration } \\
\text { test }(\mathrm{mL})\end{array}$ \\
\hline First filling_V1 & 547.17 & 547.17 & 4956 \\
Second filling_V2 & 547.17 & 547.17 & 4956 \\
\hline
\end{tabular}

was recorded every minute. Filter cake properties and turbidity were measured after the end of the test. The volume of the slurry used for all three tests have been summarized in Table 3.

\section{Results and Discussion}

\section{Pressure Filtration Test}

Two trial of PFT were performed in order to ensure reproducibility. The dewatering curve has been shown in Fig. 4. The first filling dewatered in -approximately 7 mins, where almost $450 \mathrm{~mL}$ (82\% of the total volume) dewatered. Once the dewatering slowed, the second filling of same concentration and volume was added. The second filling dewatered at a slightly slower rate, taking between 14 and 15 mins, about two times more than the first filling. However, the same amount of water $(450 \mathrm{~mL}, 82 \%$ of the second filling) was dewatered in the second filling compared with the first filling. The reason behind slow dewatering during second filling is due to the formation of the filter cake from the first filling. The filter cake reduced the permeability of the system, and subsequently the dewatering rate decreased. It can be seen that after the formation of stable filter cake, the dewatering rate is governed by the permeability of the filter cake rather than the geotextile. The variability in test results may be due to the disturbance 


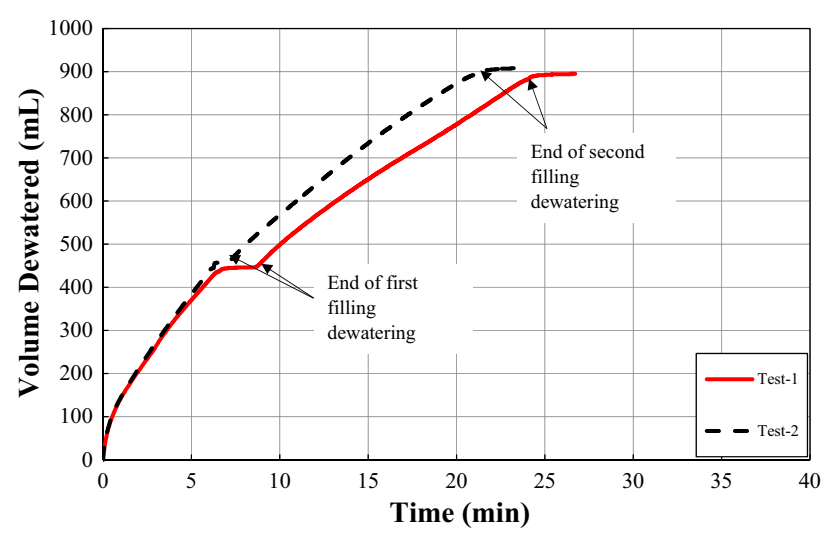

Fig. 4 Dewatering curve from PFT test

Table 4 Dewatering performance from the PFT

\begin{tabular}{lll}
\hline & Test 1 & Test 2 \\
\hline Solids content $(\%)$ & 69 & 69 \\
Height of the filter cake $(\mathrm{cm})$ & 5.3 & 4.8 \\
Diameter of the filter cake $(\mathrm{cm})$ & 7.2 & 7.2 \\
Soil loss $\left(\mathrm{g} / \mathrm{m}^{2}\right)$ & 86.5 & 72.3 \\
Soil loss $(\%)$ & 0.20 & 0.20 \\
Turbidity (NTU) & 41.2 & 27.1 \\
\hline
\end{tabular}

of the filter cake from air reduction and cap removal done to add the second filling. After the end of second filling and dewatering, filter cake properties were measured. The dewatering performance test results of the PFT has been summarized in Table 4. It can be seen that the average solids content of the filter cake from the PFT is $69 \%$. The height of the filter cake ranged from 4.8 to $5.3 \mathrm{~cm}$. The percent of soil loss was around $0.2 \%$. It was observed that the soil loss happened only during the first filling at very initial stage of filter cake formation. The soil loss during the second filling was almost zero due to the formation of filter cake. The turbidity of the filtrate collected after end of the test was below $50 \mathrm{NTU}$, and ranged from 27.1 to 41.2 NTU.

\section{Suction Filtration Test}

The dewatering results of this test are shown in Fig. 5. The first filling of the Suction Filtration Test took about 9 mins to completely dewater. Once dewatering slowed at around $490 \mathrm{~mL}$ ( $89 \%$ of the first filling), the second filling of same concentration and volume was added. The second filling dewatered at a slightly slower rate, taking 24 mins, about 2.6 times more than the first filling. Slightly less water $(440 \mathrm{~mL}, 80 \%$ of the second filling) was dewatered in the second filling as opposed to the first filling. Filter

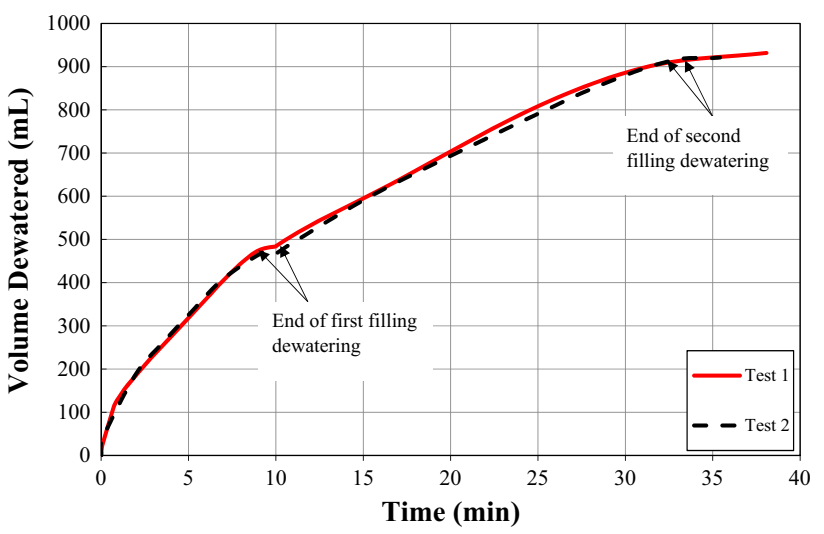

Fig. 5 Dewatering curve from suction filtration test

Table 5 Dewatering performance from the suction filtration test

\begin{tabular}{lll}
\hline & Test 1 & Test 2 \\
\hline Solids content $(\%)$ & 69 & 70 \\
Height of the filter cake $(\mathrm{cm})$ & 4.1 & 4.4 \\
Diameter of the filter cake $(\mathrm{cm})$ & 7.6 & 7.6 \\
Soil loss $\left(\mathrm{g} / \mathrm{m}^{2}\right)$ & 221.6 & 314.4 \\
Soil loss $(\%)$ & 0.56 & 0.80 \\
Turbidity (NTU) & 80.2 & 112.4 \\
\hline
\end{tabular}

cake properties were recorded at the end of the second filling. The dewatering test results from Suction Filtration Test has been summarized in Table 5. The solids content of the filter cake ranged from 69 to $70 \%$. The soil loss was ranged from 221 to $314 \mathrm{~g} / \mathrm{m}^{2}$ which corresponds to $0.56-0.80 \%$. The turbidity of the filtrate ranged from 80.2 to 112.4 NTU.

\section{PFT versus Suction Filtration Test}

Results from both one dimensional tests were similar in solids content of the filter cake. Both dewatered in about 7-10 min for the first filling, while the second filling took about 15-25 min to dewater. However, when PFT setup dewatered the slurry in about 25 mins, it took the same slurry to dewater in Suction Filtration setup in about 35 mins. Hence, it can be said that PFT tests dewaters slightly faster on average. It was also seen that the soil loss in Suction Filtration test (average of $268 \mathrm{~g} / \mathrm{m}^{2}$ ) was much higher than seen from the PFT $\left(79.4 \mathrm{~g} / \mathrm{m}^{2}\right)$. As a result, turbidity of the filtrate collected from the Suction Filtration Test was higher than from the PFT.

\section{Two Dimensional Tests}

As in case of 1-D tests, two fillings were performed for 2$D$ dewatering tests. The filtrate and filter cake properties 


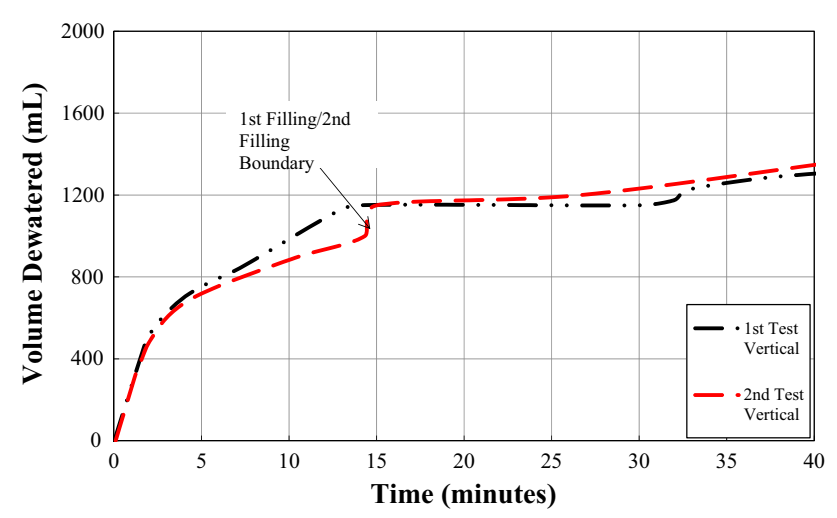

Fig. 6 Dewatering curve for vertical flow in $2 D$ test

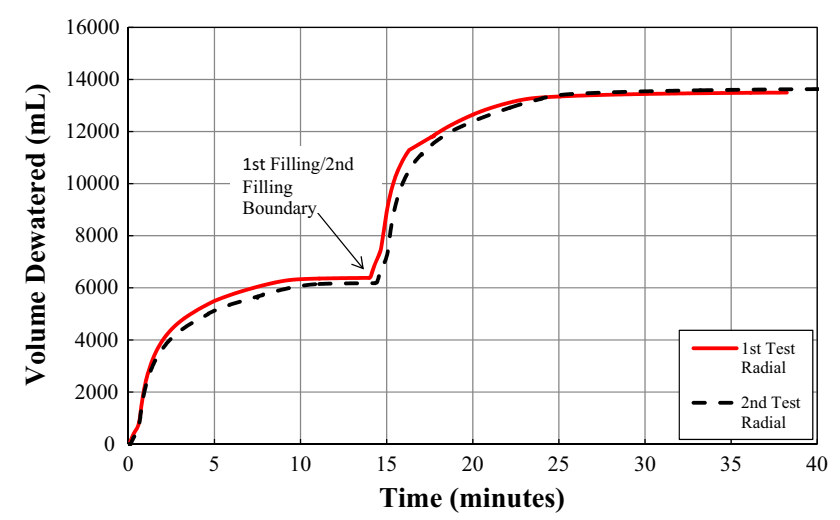

Fig. 7 Dewatering curve for radial flow in $2 D$ test

were measured at the end of dewatering from the second filling. It was observed that the first filling dewatered in approximately 15 mins. Specifically, the dewatering occurred rapidly during the first 5 mins and proceeded slowly thereafter because of the formation of vertical filter cake. During the first filling, $1150 \mathrm{~mL}$ dewatered from the vertical direction, whereas approximately $6195 \mathrm{~mL}$ dewatered from the radial direction. The dewatering results for vertical and radial flow has been shown in Figs. 6 and 7 respectively. The comparison of total flow with radial and vertical flow is shown in Fig. 8. The difference in radial vs vertical dewatering rates is due to the formation of a filter cake on the bottom geotextile through which the vertical dewatering is taking place (see Fig. 9). Due to the formation of this filter cake, the permeability decreases in the vertical direction. As a result, majority of the dewatering occurs in the radial direction. The vertical and radial dewatering comprised 15.45 and $83.25 \%$ of the total volume dewatered during the first filling. The ratio of radial to vertical dewatering was 5.38 .

After the first filling, a second filling of the same volume and solids concentration $(9912.03 \mathrm{~mL}$ at $20 \%$ solids concentration) was added to the setup. As seen in case of the first filling, dewatering was rapid during the first $5 \mathrm{~min}$

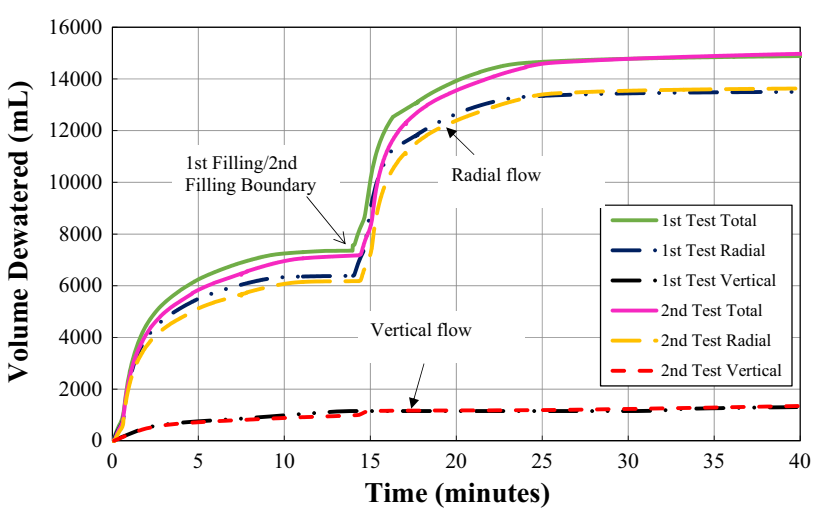

Fig. 8 Comparison of total dewatered flow with radial and vertical flow

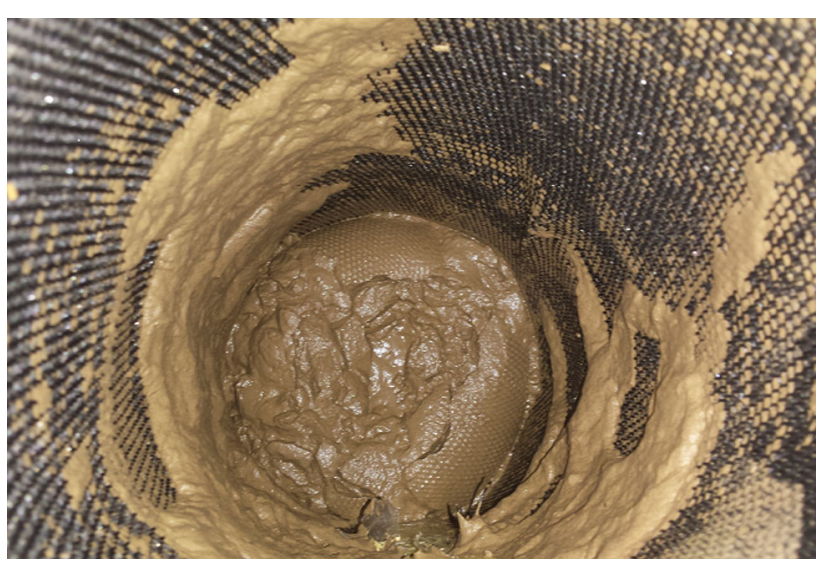

Fig. 9 Filter cake after first filling in 2-D test

and proceeded gradually thereafter with total dewatering achieved around 35-40 min. However, during the second filling the volume dewatered from the vertical direction dropped significantly from 1150 to $220 \mathrm{~mL}$ compared to the first filling. It corresponds to almost $80 \%$ drop in dewatering compared to the first filling. On the other hand, the volume dewatered from the radial direction increased from 6193 to $7434 \mathrm{~mL}$ during the second filling. During the second filling, the radial flow contributed to $98 \%$ of the total flow whereas the vertical flow contributed just $2 \%$. The ratio of radial to vertical flow during the second filling increased from 5.38 to 38.79 compared to the first filling. This is due to the reduced permeability because of the filter cake in the vertical direction.

Solids content of the vertical filter cake ranged for $67-72 \%$. Soil loss was much lower $\left(102-331 \mathrm{~g} / \mathrm{m}^{2}\right)$ than standards, with most occurring radially rather than vertically. Turbidity of the filtrate ranged from 19.1 to 26 NTU. Initially, turbidity was high as there was an initial soil loss, but it decreased as the filter cake formed. Soil loss was greater radially than vertically due to the lack of a large filter cake on the sides of the geotextile. The dewatering 
Table 6 Dewatering performance from $2 D$ tests

\begin{tabular}{lll}
\hline & Test 1 & Test 2 \\
\hline Solids content $(\%)$ & $67-72$ & $63-67$ \\
Height of the filter cake $(\mathrm{cm})$ & $19.5-21$ & $19-20.5$ \\
Diameter of the filter cake $(\mathrm{cm})$ & 15 & 15 \\
Soil loss $\left(\mathrm{g} / \mathrm{m}^{2}\right)$ & 331 & 102 \\
Soil loss $(\%)$ & 1.7 & 0.3 \\
Turbidity (NTU) & 26.1 & 19 \\
\hline
\end{tabular}

performance from the 2D tests have been summarized in Table 6.

\section{Discussion}

The PFT and Suction Filtration apparatuses, while not similar in form, are similar in function. The PFT apparatus is designed to add pressure by air at the top of the dewatering column, creating an additional force to gravity to push water through the geotextile. It begins at a pressure of $5.5 \mathrm{kPa}$ and naturally lessens throughout the test. This is because as dewatering proceeds, water leaves the system and the air can fill a greater area. This was compensated for by increasing pressure back up to $5.5 \mathrm{kPa}$ throughout the test, to allow for suction test comparison. The Suction Filtration apparatus is designed at a specific height to create a pressure gradient of $5.5 \mathrm{kPa}$ between the top and bottom of the apparatus through the removal of air. The height by which the pressure gradient is created never changes, so dewatering is done at a constant and regulated rate. The apparatuses are analogous as they are both one dimensional tests using a pressure of $5.5 \mathrm{kPa}$ to facilitate dewatering, and their resemblance is apparent in the test results as discussed earlier.

Conversely, the two-dimensional test apparatus dewaters both radially and vertically, and no pressure is exerted on the system other than gravity. The apparatus is designed at a height of $60 \mathrm{~cm}$, which produces a pressure of $5.5 \mathrm{kPa}$ on the system when filled with slurry. The pressure can be dissipated radially as well as vertically throughout the test. As dewatering proceeds, similar to the PFT apparatus, pressure lessens on the system. With the addition of a second filling this can temporarily be brought back up to $5.5 \mathrm{kPa}$, but additional controls on the system are not possible. These conditions are favorable however, as the process of pressure attenuation creates conditions much more representative of real life dewatering applications.

Unlike the one-dimensional test apparatuses, the slurry in the two-dimensional test apparatus can dewater both vertically and radially. Radial drainage was determined to be a large factor in dewatering time, as nearly $80 \%$ of the total slurry dewatered through the sides. Dewatering will occur wherever the fastest and easiest path is present. Time of dewatering is governed by both the geotextile and the filter cake, but due to the lower permeability of the filter cake, most dewatering occurs radially. This explains why both 1 st and 2nd fillings dewatered in the same time. Sediment on the sides of the geotextile would fall from the sides leading to the edges of the sediment being slightly higher than the middle. This may be the reason for the higher water content in the middle of the apparatus. These processes demonstrate a condition that is much more representative of real life dewatering applications, in which the filter cake is not a clean formation.

Solids content was on average $62 \%$ for one filling whereas it was $69 \%$ for two fillings. Dewatering was not as productive in the one-filling two-dimensional tests than the two fillings due to the added weight and pressure on the system. Using the two fillings test comparisons, dewatering rate was much faster with two-dimensional dewatering versus one-dimensional due to radial dewatering.

\section{Conclusion}

The two-dimensional test is comparative in function to the HBTs used on dewatering sites. However, unlike HBTs, the two-dimensional test apparatus is designed to create results similar to real life conditions for additional testing in the laboratory. It is evident that the creation of a twodimensional filtration apparatus for use in a laboratory setting can be of great benefit to a multitude of people, including researchers, mathematicians, and field operators. Because the two-dimensional apparatus can easily identify radial drainage from vertical drainage, a mathematical model may be produced that would reduce the need and cost of experimental testing in construction projects. However, at this time, a couple improvements on the apparatus need to be made, including a more structurally sound form and reproducible testing method. The form is currently not able to be replaced with a new woven geotextile simply. A simpler and easier method of slurry mixing and addition to the apparatus would also be of great benefit.

Acknowledgments This study was supported by the National Science Foundation (NSF) Grant No. CMMI 110031. The geotextile was provided by TenCate. The Suction Filtration Test was conducted at the Department of Paper and Bioprocess Engineering at SUNY-ESF with the help of Dr. Bandaru Ramarao. The authors would like to acknowledge this support.

\section{References}

1. Yee TW, Lawson CR (2012) Modelling the geotextile tube dewatering process. Geosynth Int 19(5):339-353 
2. Kutay ME, Aydilek AH (2004) Retention performance of geotextile containers confining geomaterials. Geosynth Int 11(2):100-113

3. Grzelak MS, Maurer BW, Pullen TS, Bhatia SK, Ramarao BV (2011) A comparison of test methods adopted for assessing geotextile tube dewatering performance. In: Proceedings of GeoFrontiers 2011, pp 2141-2151

4. Aydilek AH, Edil TB (2002) Filtration performance of woven geotextiles with wastewater treatment sludge. Geosynth Int 9(1):41-69

5. Liao K, Bhatia SK (2005) Geotextile tube: filtration performance of woven geotextiles under pressure. In: Proceedings of NAGS 2005/GRI-19 cooperative conference, Las Vegas

6. Montero CM, Overmann LK (1990) Geotextile filtration performance test. In: Koerner RK (ed) Geosynthetic testing for waste containment applications, vol 1081. ASTM STP, pp 273-284

7. Moo-Young H, Myers TE, Townsend D, Ochola C (1999) The migration of contaminants utilized in dredgings operations. Eng Geol 53:167-176

8. Moo-Young HK, Gaffney DA, Mo X (2002) Testing procedures to assess the viability of dewatering with geotextile tubes. Geotext Geomembr 20(5):289-303
9. Muthukumuran AE, Ilamparuthi K (2006) Laboratory studies on geotextile filters used in geotextile tube dewatering. Geotext Geomembr 24:210-219

10. Satyamurthy R, Bhatia S (2009) Effect of polymer conditioning on dewatering characteristics of fine sediment slurry using geotextiles. Geosynth Int 16(2):83-96

11. Moo-Young HK, Tucker WR (2002) Evaluation of vacuum filtration testing for geotextile tubes. Geotext Geomembr 20(3):191-212

12. Huang CC, Luo SY (2007) Dewatering of reservoir sediment slurry using woven geotextiles. Geosynth Int 14(5):253

13. Baker KB, Chastain JP, Dodd RB (2002) Treatment of lagoon sludge and liquid animal manure utilizing geotextile filtration. ASABE paper no. 024128, St. Joseph

14. Ramarao B (1997) Analysis of cake growth in cake filtration: effect of fine particle retention. AlChE J 43(1):33-44

15. Spritzer JM, Khachan MM, Bhatia SK (2015) Influence of synthetic and natural fibers on dewatering rate and shear strength of slurries in geotextile tube application. Int J Geosynth Ground Eng 1(3):1-14. doi:10.1007/s40891-015-0027-1 